\title{
CRITICAL REVIEW: \\ EFEK DARI HETEROGENITAS BOARD CAPITAL TERHADAP STRATEGIC CHANGE
}

\author{
Jean Richard Jokhu, President University \\ Jean.richard@president.ac.id
}

\begin{abstract}
Abstrak
Penelitian dalam ranah dewan direksi didominasi oleh pembahasan akan diversivikasi para direksi. Pada studi ini peneliti berusaha untuk mengeksplorasi penelitian miliki Hayman dan Hilman (2010) yang menggaris bawahi diversivikasi dewan direksi sebagai salah satu masalah dalam keunggulan daya saing yang dapat memperkuat kinerja perusahaan. Dengan menggunakan kaca mata stratejik manajemen studi ini sekaligus menambahkan perspektif manajemen perubahan sebagai salah satu outcome dari diversifikasi dewan direksi.
\end{abstract}

Kata Kunci:Manajemen Stratejik, Perubahan Stratejik, Dewan Pemilik Modal, Kinerja Perusahaan

\begin{abstract}
Abstrac
Many board of directors research was dominated by director diversification. In this study the researcher try to explore Hayman and Hilman (2010) research that enforce board of directors diversification as on of competitive advantage of the firm that strengten firm performance. Using strategic management lenses we provide new perspective and also adding change management as one of the outcome of direction diversification.
\end{abstract}

Keyword : Strategic Management, Strategic Change, Board of Capital, Firm Performance

\section{A. Latar Belakang}

Penelitian mengenai dewan direksi atau dewan modal merupakan penelitian yang paling sering ditemukan pada jurnal strategi (Whellen, Hunger, Hoffman, dan Bamford, 2017). Pengertian mengenai dewan direksi sendiri berubah saat sebuah perusahaan menjadi entitas yang besar dari sebuah homogenitas unit menjadi sebuah institusi yang merencanakan dan mengaplikasikan suatu strategi (De Masis, Wang \& Chua, 2018). Kondisi ini menjadi salah satu alasan mengapa fokus dari para peneliti adalah bagaimana kondisi "dewan direksi” sebagai institusi internal yang mempengaruhi performa dari perusahaan. Berdasarkan penelitian terdahulu ditemukan beberapa pandangan terhadap efek dari heterogenitas dewan direksi terhadap performa perusahaan (Daspit, Chisman, Sharma, Pearson, \& Mahto, 2016).

Studi ini dilakukan untuk mengeksplorasi teori dewan direksi Hayman dan Hilman (2010) sebagai bagian intergrasi perubahan strategis yang mempengaruhi kinerja perusahaan. Penelitian ini diharapkan dapat memberikan teori yang dapat menguatkan konsep dari dewan direksi 
sebagai faktor yang mempengaruhi perubahan stratejik. Pada bagian berikutnya akan dijelaskan konsep dari dewan direksi dan perubahan stratejik serta pengaruhnya terhadap kinerja perusahaan.

\section{B. Landasan Theori}

\section{Dewan Direksi}

Beberapa perspektif berkembang akan dampak dari dewan direksi perusahaan. Pandangan pertama melihat bahwa heterogenitas dari dewan direksi sebagai keunggulan daya saing, karena mampu memberikan masukan dan pandangan baru untuk mengakuisisi sumber daya pada lingkungan eksternal maupun internal (Mintzberg, 1983; Pearce dan Zahra, 1992; Pfeffer, 1972). Sedangkan pandangan kedua melihat bahwa heterogenitas tidak berpengaruh banyak terhadap kinerja dari perusahaan, namun hanya mempertimbangkan apakah keputusan yang diambil sudah obyektif, independen, dan mampu mengatasi perang kepentingan dari pihak internal (Williamson, 1975;Kosnik, 1987; Singh dan Harianto, 1989).

Dewan direksi atau board of directors (BOD) sendiri merupakan sebuah entitas yang didalamnya memiliki human dan social capital, yang memiliki kemampuan untuk memberikan masukan dan menformulasi strategi, dan memiliki akses terhadap informasi dan sumberdaya yang diperoleh melalui skills, expertise, dan legitimacy (Pfeffer dan Salancik, 1978; Wheelen et al., 2017; Dixon-Fowler et al., 2017). Namun disisi lain hadirnya faktor manusia dalam BOD memungkinkan untuk terjadinya kepentingan untuk saling mempengaruhi (Colemen, 1988; Nahapiet dan Ghoshal, 1988; Yarbrough, Abebe, \& Dadanlar, 2017) atau sering disebut dengan politik (Eisenhardt dan Zbaracki, 1992). Berangkat dari fenomena tersebut, menurut Hayness dan Hillman (2010) dalam menghadapi benturan kepentingan yang terjadi dalam BOD dilakukan dengan cara mengatasi interdependensi yang terjadi dalam suatu organisasi. Dengan memodelkan BOD yang dapat membatasi timbulnya kepentingan individu dan mengembalikan fungsi BOD sesuai dengan kemampuannya.

Haynes dan Hillman (2010) menggunakan Dua dimensi breadth dan depth sebagai alat untuk menjelaskan heterogenitas BOD. BOD Breadth adalah heterogenitas latar belakang dari direktur yang dilihat dari pengalaman kerja, relasi, dan fungsinya (O'Shannassy, 2015). BOD depth adalah heterogenitas kedalaman BOD dalam menekuni atau menguasai industri dari perusahaan. Penelitianya berisi tentang pengaruh BOD breadth dan BOD depth terhadap Strategic Change. Strategic Change yang dioprasionalisasikan oleh dua komponen. Pertama strategic variation, perubahan pola penggunaan alokasi sumber daya. Kedua strategic deviation, perubahan norma penggunaan alokasi sumber daya (Carpenter, 2000; O’Shannassy, 2015).

Berangkat dari perspektif tersebut review ini ingin membandingkan dengan pandangan yang sebelumnya telah ada dan pandangan yang berkembang setelah penelitian ini. Penelitian dari Haynes dan Hillman (2010) adalah pembuktian terhadap hubungan antara heterogenitas 
perusahaan dengan Strategic Change yang berdampak pada performa perusahaan. Pada penelitian sebelumnya yang dilakukan oleh Goodstein, Gautam, dan Boeker (1994) performa Strategic Change dipengaruhi oleh keragaman anggota dari board of directors. Sedangkan penelitian sesudahnya yang dilakukan oleh Quigley dan Hambrick (2012) tentang bagaimana Strategic Change dipengaruhi oleh successor discretion dan Strategic Change terhadap performa perusahaan.

ketiga penelitian ini menarik karena menemukan hasil yang berbeda - beda. Dengan menggunakan Haynes dan Hillman (2010) sebagai jurnal utama dalam melakukan critical review terhadap jurnal tersebut dengan menggunakan jurnal - jurnal yang membicarakan akan pengaruh keragaman BOD terhadap Strategic Change yang berdampak pada performa perusahaan.

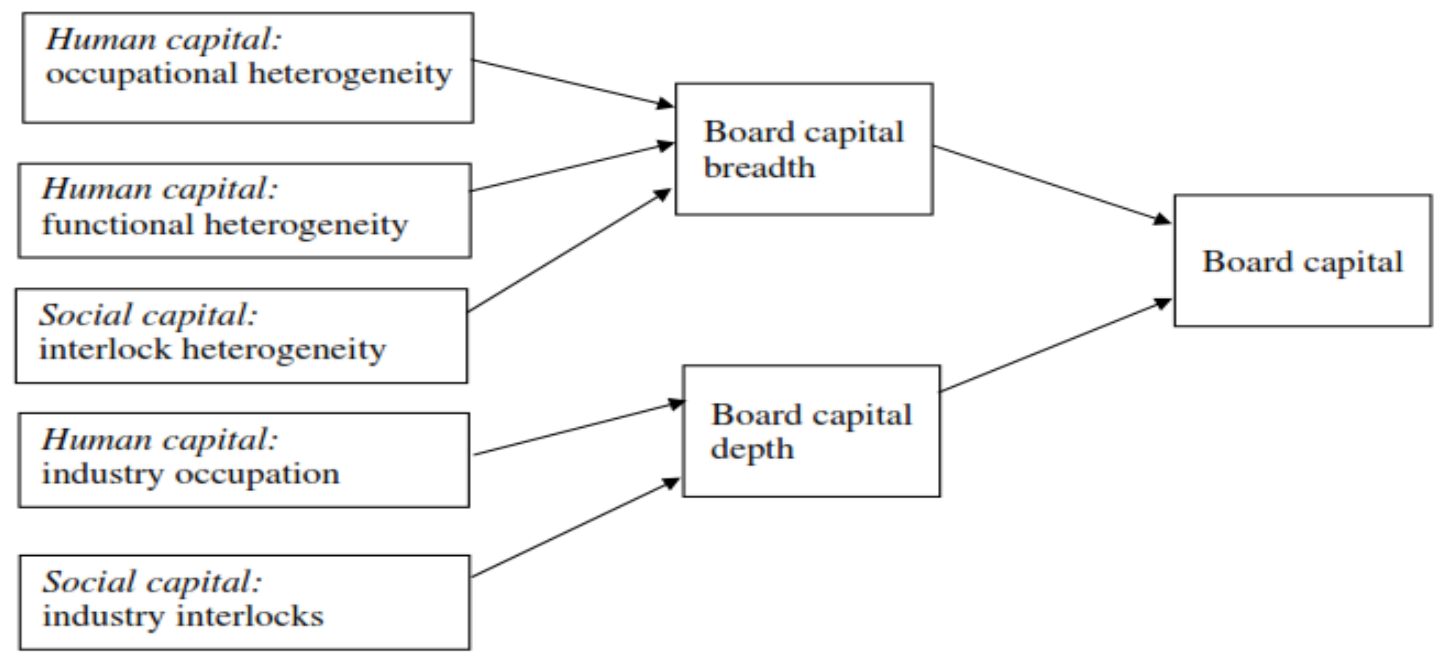

Gambar 1.1 Model penelitian dari Heynes dan Hillman (2010)

\section{Strategic Change}

Banyak teori stratejik manajemen memiliki perspektif bahwa keberagaman BOD memberikan keuntungan bagi perusahaan karena mampu memfasilitasi untuk mendapatkan critical resource untuk organisasi (Pfeffer, 1972, 1973; Pfeffer dan Slancik, 1978; Erhardt, Werbel, \& Shrader, 2003). Corporate governance theorist juga berpendapat bahwa keberagaman BOD dapat memberikan keuntungan bagi Organisasi baik langsung maupun tidak langsung (Kosnik, 1990), karena mampu memberikan perspektif baru, dan memberikan solusi baru dalam segala hal tentang pengambilan keputusan (Eisenhardt dan Bourgeois, 1988; Scheiger, Sandberg, dan Ragan, 1986; Bezemer et al., 2018).

Namun keberagaman anggota BOD tidak menjamin kecepatan dalam pengambilan keputusan khususnya dalam lingkungan yang berubah - ubah (Goodstein et al., 1994). Anggota dari BOD 
pasti akan membawa kepentingan individu didalamnya(Baysingar dan Butler, 1985; Kosnik, 1990). Perbedaan kepentingan berasal dari latar belakang pengalaman kerja, demografi dan professionalisme (Powel, 1991; Thompson, 1967; Hoseini et al., 2019) menyebabkan adanya keberagamana persepsi dalam Strategic Change. Semakin kuat perbedaan yang terjadi dalam BOD maka semakin besar potensi dalam menimbulkan konflik dan faksi yang berkembang akibat perbedaan perspektif atas tujuan dan kebijakan organisasi (Clegg, 1990; Mintzberg, 1983; Powell, 1991).

keberagaman latarbelakang dan pengalaman dari anggota BOD, ditambah dengan isu yang mempengaruhi pengambilan keputusan justru meningkatkan ketidakpastian dan konflik dalam diri BOD (Mintzberg, 1983). Dengan meningkatnya perbedaan antara individu dan koalisi justru memperparah proses pengambilan keputusan terhadap Strategic Change (Walsh et al, 1988).

Secara keseluruhan Goodstein, Gautam, dan Boeker (1994) melihat bahwa keberagaman BOD justru menciptakan konflik baik dalam pengambilan keputusan maupun dalam melakukan Strategic Change. Berbeda dengan penelitian itu Hayness dan Hillman (2010) melakukan penelitian dan mendapatkan bahwa keberagaman anggota dari BOD justru membawa nilai - nilai baru dalam proses Strategic Change. Hadirnya 'orang baru' dalam BOD ustru mencipakan inertia breaker yang dapat melepaskan perusahaan dari inertia path yang justru memberikan kepastian semu dalam performa perusahaan (Quigley dan Hambrick, 2012).

Dalam penelitianya Hayness dan Hillman justru (2010) menemukan bahwa adanya perbedaan baik dalam latarbelakang fungsional BOD maupun dalam Embeddedness dalam BOD. Namun hasil penelitianya tidak mengecilkan fungsi dari CEO. CEO berperan sebagai fasilitator terhadap kebijakan yang diciptakan oleh BOD, namun CEO juga bisa berbalik menyeang kebijakan BOD yang tidak sesuai dengan kepentinganya. Haynes dan Hillman (2010) melihat bahwa peran CEO dalam memoderasi lancarnya Strategic Change. Selain itu penelitian ini juga menemukan bahwa semakin beragam suatu BOD maka semakin banyak pengetahuan, pengalaman, dan social ties yang dimiliki sehingga semakin besar kemampuan perusahaan untuk melakukan Strategic Change.

\section{Metodologi}

Jurnal ini bertujuan untuk mengkritisi kembali teori dari dewan direksi atau BOD yang dikemukakan Hayhness dan Hilman (2010) dengan pendekatan manajemen strategi. Studi ini adalah bentuk model konseptual dari dewan direksi dengan menggunakan tinjauan literatur dari berbagai penelitian, sehingga dapat memberikan masukan tentang teori dewan direksi dalam perspektif manajemen perubahan. Studi ini menggunakan metode dokumentasi yang didasari oleh data sekunder yang diperoleh melalui jurnal - jurnal dengan topik dewan direksi dan manajemen stratejik 20 tahun terakhir. 


\section{Pembahasan}

Dalam studi ini peneliti melihat hal yang menarik dari penelitian penelitian BOD yakni keberagaman latar belakang dari BOD justru memberikan nilai tambah dalam memberikan kontribusi dalam mendorong terciptanya Strategic Change (Hayness dan Hillman, 2010). Sebaliknya penelitian sebelumnya Goodstein et al. (1994) melihat keberagaman atau heterogenitas BOD berdampak buruk bagi proses pengambilan keputusan khususnya proses Strategic Change yang didalamnya pasti terjadi perang kepentingan. Khususnya bagi para manager yang telah lama (embedded) dalam indutri tersebut sehingga akan selalu mempertahankan status quo yang dimiliki.

Selanjutnya, masih menjadi kritik terhadap jurnal dari Hayness dan Hillman (2010) yang mengatakan bahwa keberagaman dapat meningkatkan munculnya ide baru yang dapat meningkatkan kinerja dari perusahaan. Westphal dan Bednar (2005) menjelaskan bahwa pluralistic dalam BOD tidak menjamin terjadinya suatu consensus dalam pengambilan keputusan, yang terjadi justru para anggota mempertahankan status quo bahkan cendrung menolak adanya perubahan. ini artinya selain latar belakang proses pengambilan keputusan pun berdampak buruk bagi Strategic Change yang akan dilakukan (Gambar 2). Dengan demikian perlu rasanya untuk melakukan penelitian yang dapat memperkuat peran dari Breadth dan Depth dari dewan direksi terhadap kinerja perusahaan (Gambar 2)

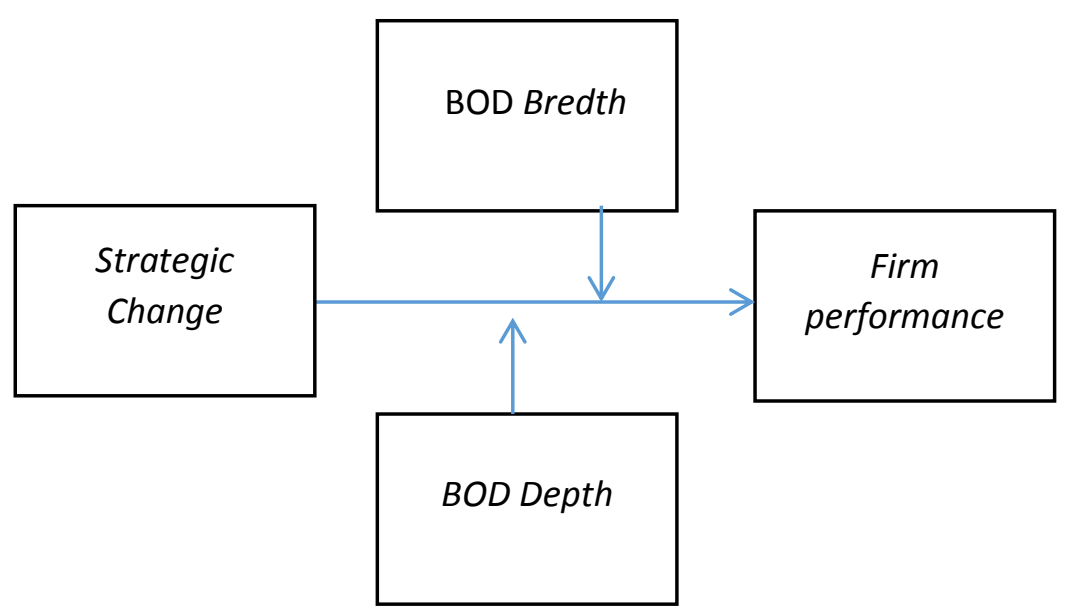

Gambar 2. Proposisi konseptual model dari penelitian Hayman dan Hilman (2010)

\section{E. Simpulan dan Saran}




\section{Simpulan}

Sampai sekarang belum ada yang bisa memastikan dampak baik atau buruk dari keberagaman anggota BOD. Seperti yang dijelaskan sebelumnya, keberagaman dapat berdampak baik jika masing - masing dapat memberikan ide dan masukan yang berharga bagi perusahaan. Namun sebaliknya ide dari masing - masing anggota tidak bisa dipungkiri bisa sarat akan kepentingan individu oleh karena itu belum tentu dapat memberikan masukan berharga sehingga bisa - bisa BOD kembali menjadi entitas yang homogen.

Selain dari intensi dalam pengambilan keputusan, dalam konteks lingkungan pun banyak sekali perbedaan pendapat. Keadaan lingkungan yang berubah - ubah mengharuskan organisasi untuk berubah oleh karena itu harus menggunakan ide yang berbeda, untuk itu diperlukanlah adanya keberagaman BOD sehingga dapat memberikan perspektif yang berbeda - beda akan bagaimana cara mengatasi hal ini (Kosnik, 1990; Epstein, Angert, \& Stain, 2017). Sedangkan penelitian lain justru berpendapat keadaan lingkungan yang berubah - ubah justru mengharuskan BOD yang homogen (Pfeffer dan Slancik, 1978), maksudnya adalah agar tidak menciptakan Strategic Change yang terlalu berbeda sehingga justru merugikan perusahaan. Keberadaan Breadth dan Depth seharusnya memperkuat kinerja perubahan stratejik perusahaan karena memiliki kekayaan cognitif hasil dari perbedaan keduanya.

\section{Saran}

Oleh karena itu, studi ini menjelaskan urgensi dari konseptual pada gambar 2 untuk penelitian selanjutnya menguji dimensi breadth dan depth terhadap proses perubahan stratejik dalam perusahaan yang dipengaruhi oleh kondisi BOD yang heterogen. Dalam konteks manajemen perubahan perlu untuk melakukan penelitian dengan menggunakan diversifikasi para direksi untuk menjelaskan perbedaan kinerja yang terjadi di perusahaan yang memiliki direksi homogen dan heterogen.

\section{F. Daftar Pustaka}

Bezemer, P. J., Nicholson, G., \& Pugliese, A. (2018). The Influence Of Board Chairs On Director Engagement: A Case-Based Exploration Of Boardroom Decision-Making. Corporate Governance: An International Review, 26(3), 219-234.

Carpenter, M. A., \& Westphal, J. D. (2001). The Strategic Context Of External Network Ties: Examining The Impact Of Director Appointments On Board Involvement In Strategic Decision Making. Academy Of Management Journal, 44(4), 639-660.

Clegg, S. (1990). Modern Organizations: Organization Studies In The Postmodern World. Sage.

De Massis, A., Wang, H., \& Chua, J. H. (2019). Counterpoint: How Heterogeneity Among Family Firms Influences Organizational Change. Journal Of Change Management, 19(1), 37-44.

The Role Of Board Environmental Committees In Corporate Environmental Performance 
Daspit, J. J., Chrisman, J. J., Sharma, P., Pearson, A. W., \& Mahto, R. V. (2018). Governance As A Source Of Family Firm Heterogeneity.

Eisenhardt, K. M. (1989). Making Fast Strategic Decisions In High-Velocity Environments. Academy Of Management Journal, 32(3), 543-576.

Eisenhardt, K. M., \& Bourgeois Iii, L. J. (1988). Politics Of Strategic Decision Making In HighVelocity Environments: Toward A Midrange Theory. Academy Of Management Journal, 31(4), 737-770.

Epstein, D., Angert, C., \& Strain, C. (2017). Board Of Director Composition, And Ownership And Their Relationship To Patents: An Empirical Study. Journal Of Marketing Development And Competitiveness, 11(2), 78-87.

Erhardt, N. L., Werbel, J. D., \& Shrader, C. B. (2003). Board Of Director Diversity And Firm Financial Performance. Corporate Governance: An International Review, 11(2), 102-111.

Goodstein, J., Gautam, K., \& Boeker, W. (1994). The Effects Of Board Size And Diversity On Strategic Change. Strategic Management Journal, 15(3), 241-250.

Haynes, K. T., \& Hillman, A. (2010). The Effect Of Board Capital And Ceo Power On Strategic Change. Strategic Management Journal, 31(11), 1145-1163.

Hoseini, M., Safari Gerayli, M., \& Valiyan, H. (2019). Demographic Characteristics Of The Board Of Directors' Structure And Tax Avoidance: Evidence From Tehran Stock Exchange. International Journal Of Social Economics, 46(2), 199-212.

Kosnik, R. D. (1987). Greenmail: A Study Of Board Performance In Corporate Governance. Administrative Science Quarterly, 163-185.

Mintzberg, H., \& Mintzberg, H. (1983). Power In And Around Organizations (Vol. 142). Englewood Cliffs, $\mathrm{Nj}$ : Prentice-Hall.

Oehmichen, J., Heyden, M. L., Georgakakis, D., \& Volberda, H. W. (2017). Boards Of Directors And Organizational Ambidexterity In Knowledge-Intensive Firms. The International Journal Of Human Resource Management, 28(2), 283-306.

O'shannassy, T. (2015). Strategic Management Research In The Journal Of Management \& Organization: International In Orientation With An Australasian Edge. Journal Of Management \& Organization, 21(5), 551-557.

Pearce, J. A., \& Zahra, S. A. (1991). The Relative Power Of Ceos And Boards Of Directors: Associations With Corporate Performance. Strategic Management Journal, 12(2), 135-153.

Pearce, J. A., \& Zahra, S. A. (1992). Board Composition From A Strategic Contingency Perspective. Journal Of Management Studies, 29(4), 411-438. 
Pfeffer, J., \& Salancik, G. R. (2003). The External Control Of Organizations: A Resource Dependence Perspective. Stanford University Press.

Pfeffer, J. (1972). Size And Composition Of Corporate Boards Of Directors: The Organization And Its Environment. Administrative Science Quarterly, 218-228.

Pfeffer, J. (1973). Size, Composition, And Function Of Hospital Boards Of Directors: A Study Of Organization-Environment Linkage. Administrative Science Quarterly, 349-364.

Pfeffer, J., \& Salancik, G. R. (2003). The External Control Of Organizations: A Resource Dependence Perspective. Stanford University Press.

Powell, W. W., \& Dimaggio, P. J. (Eds.). (2012). The New Institutionalism In Organizational Analysis. University Of Chicago Press.

Quigley, T. J., \& Hambrick, D. C. (2012). When The Former Ceo Stays On As Board Chair: Effects On Successor Discretion, Strategic Change, And Performance. Strategic Management Journal, 33(7), 834-859.

Schweiger, D. M., Sandberg, W. R., \& Ragan, J. W. (1986). Group Approaches For Improving Strategic Decision Making: A Comparative Analysis Of Dialectical Inquiry, Devil's Advocacy, And Consensus. Academy Of Management Journal, 29(1), 51-71.

Walsh, J. P., Henderson, C. M., \& Deighton, J. (1988). Negotiated Belief Structures And Decision Performance: An Empirical Investigation. Organizational Behavior And Human Decision Processes, 42(2), 194-216.

Powell, W. W. (1991). 'Expanding The Scope Of Institutional Analysis'. In W. W. Powell And P. J. Dimaggio (Eds.), The New Institutionalism In Organizational Analysis. University Of Chicago Press, Chicago, Il. Pp. 183-203.

Quigley T. J. Dan Hambrick D. C. (2012). When The Former Ceo Stays On As Board Chair: Effects On Successor Discretion, Strategic Change, And Performance. Strategic Management Journal. 33; $834-859$

Schweiger, D.,W. Sandberg And J. Ragan (1986). 'Group Approaches For Improving Strategic Decision Making: A Comparative Analysis Of Dialectical Inquiry, Devil's Advocacy, And Consensus', Academy Of Management Journal, 29, Pp. 51-71.

Walsh, J. P., C. M. Henderson And J. Deighton (1988). 'Negotiated Belief Structures And Decision Performance: An Empirical Investigation', Organizational Performance And Human Decision Processes, 42, Pp. 194-216.

Wheelen, T. L., Hunger, J. D., Hoffman, A. N., \& Bamford, C. E. (2017). Strategic Management And Business Policy (P. 55). Boston: Pearson. 
Williamson, O. E. (1975). Markets And Hierarchies: Analysis And Antitrust Implications: A Study In The Economics Of Internal Organization. University Of Illinois At UrbanaChampaign's Academy For Entrepreneurial Leadership Historical Research Reference In Entrepreneurship.

Yarbrough Jr, E., Abebe, M., \& Dadanlar, H. (2017). Board Political Experience And Firm Internationalization Strategy: A Resource Dependence Perspective. Journal Of Strategy And Management, 10(4), 401-416. 